\title{
Planejamento Estratégico Pessoal: a caminho de um REFERENCIAL
}

\author{
Personal Strategic Planning: on the way of a reference
}

$\Gamma$

\begin{abstract}
Marilei Osinski
Graduanda em Administração na Universidade Federal de Santa Catarina - Florianópolis - SC - Brasil. E-mail: marileiosinski@gmail. com
\end{abstract}

\section{Maurício Fernandes Pereira}

Doutor em Engenharia de Produção pela Universidade Federal de Santa Catarina. Professor Associado do Departamento de Ciências da Administração - Universidade Federal de Santa Catarina - Florianópolis - SC - Brasil.E-mail: mfpcris@gmail.com

\section{Dyogo Felype Neis}

Mestrando no Programa de Pós-Graduação em Administração da Universidade Federal de Santa Catarina - Florianópolis - SC - Brasil. E-mail: dyogoneis@hotmail.com

\section{Siqueira Morais Neto}

Doutorando no Programa de Pós-Graduação em Administração da Universidade Federal de Santa Catarina - Florianópolis - SC -

Brasil.E-mail:smneto@hotmail.com

\section{Resumo}

Este artigo pretende identificar o perfil das pessoas que utilizam o Planejamento Estratégico Pessoal e, a partir disso, avaliar os elementos teóricos e empíricos necessários para a formulação de um referencial metodológico de Planejamento Estratégico Pessoal. Ampliando a concepção de Planejamento Estratégico no âmbito organizacional para a vida pessoal, a pesquisa desenvolveu-se com base na literatura de Planejamento Estratégico Pessoal. A coleta dos dados primários foi realizada através da aplicação de um questionário com 35 questões, disponibilizado por mais de 60 dias em dois sites institucionais da UFSC - Universidade Federal de Santa Catarina. Ao todo, 345 pessoas responderam ao questionário. Dentre os resultados da pesquisa destaca-se que o sentido de "riqueza" extrapola os temas relacionados ao dinheiro, as pessoas entre a faixa etária de 26 a 30 anos são os que mais planejam e que $75 \%$ dos entrevistados utilizam alguma forma de planejamento pessoal.

Palavras-chave: Riqueza. Planejamento Estratégico Pessoal. Planejamento Estratégico.

\section{Abstract}

This article aimed to identify the profile of people who use the Personal Strategic Planning, and from this, evaluate the theoretical and empirical elements needed for the development of a methodological framework for Personal Strategic Planning. Extending the concept of Strategic Planning from the organizational to the personal life, the research is developed based on the literature of Personal Strategic Planning. The collection of primary data was conducted through a questionnaire with 35 questions, available for more than 60 days at two institutional sites of the UFSC - Universidade Federal de Santa Catarina. Altogether, 345 people responded the questionnaire. Among the results of the survey it is highlighted that the meaning of "wealth" goes beyond issues related to money, people in the age group of 26-30 years are the ones who most plan and $75 \%$ of respondents use some form of personal planning.

Keywords: Richness. Personal Strategic Planning. Strategic Planning. 


\section{INTRODUÇÃO}

Uma das formas mais populares de formulação estratégica na prática organizacional é por meio do planejamento estratégico. As primeiras discussões acerca dessa ferramenta concluíam que esse era o melhor ou único caminho para formular e implementar as estratégias no âmbito das organizações. Nesse período, o planejamento estratégico era praticamente incontestável. (MINTZBERG, 1994)

Apesar de algumas críticas e questionamentos, o planejamento estratégico continua sendo amplamente utilizado pelas organizações e é entendido pelos executivos como uma das ferramentas mais relevantes, já que prepara atores de tomada de decisão para agirem de maneira adequada diante dos inevitáveis desafios que o mercado impõe. Segundo estudo realizado periodicamente pela consultoria Bain \& Company, em 2013, o planejamento estratégico foi uma das ferramentas gerenciais mais utilizadas pelas organizações no contexto mundial, correspondendo a $43 \%$ do total de organizações pesquisadas. Além disso, entre aquelas que não o utilizam, $81 \%$ pretendem utilizá-lo no próximo ano, o que demonstra a relevância dessa ferramenta no contexto mercadológico. (RIGBY; BILODEAU, 2013)

Assim como no ambiente organizacional, o planejamento estratégico começa a assumir o seu papel no contexto pessoal, isto é, na realidade de cada indivíduo. A necessidade por se antecipar às mudanças, cada vez mais rápidas e constantes (ESTRADA; ALMEIDA, 2007) vem desenvolvendo novas necessidades no cotidiano individual das pessoas. Essas mudanças estão relacionadas tanto com o âmbito profissional, na procura por diferenciais competitivos, quanto na esfera pessoal, na busca pela autorrealização. Diante desse cenário, o Planejamento Estratégico Pessoal tornou-se objeto de estudo de diversos pesquisadores. (ESTRADA; MORETTO NETO; AUGUSTIN, 2011)

Especialmente por se tratar de um tema relativamente recente, pode-se afirmar que ainda são poucas as propostas de modelos de Planejamento Estratégico Pessoal na literatura. Entretanto, embora não utilizem essa nomenclatura, é possível constatar alguns referenciais que de alguma forma buscam auxiliar os indivíduos a formularem estratégias para a sua vida pessoal, como é o caso dos modelos de Souza (2003), Seiwert
(2004) e Cygler (2005). No que se refere aos modelos de Planejamento Estratégico Pessoal propriamente dito, destacam-se os referenciais de Koshy (2005) e Estrada, Moretto Neto e Augustin (2011).

Contudo, não há referências que possam identificar o perfil das pessoas que utilizam o Planejamento Estratégico Pessoal, isto é, seus consumidores. Entende-se que essa seja uma prerrogativa fundamental para a proposta de um referencial metodológico mais condizente com a realidade e capaz de implementar as estratégias formuladas. Sabendo que as principais críticas ao planejamento estratégico estão relacionadas à dificuldade de implementação das estratégias, ainda que muitas delas surjam em decorrência da não compreensão de seu conceito e de sua prática (BEPPLER; PEREIRA, 2013), acredita-se que o entendimento do perfil dos consumidores do Planejamento Estratégico Pessoal seja essencial para o futuro desenvolvimento de um referencial metodológico que realmente esteja de acordo com a realidade de cada indivíduo.

Diante desse contexto, este artigo pretende identificar quais são os aspectos teóricos e empíricos que devem compor um referencial metodológico de Planejamento Estratégico Pessoal, a partir do perfil dos seus consumidores. Além de poder impulsionar os estudos científicos sobre o tema, esta pesquisa, em um panorama mais amplo, pretende servir como base para o desenvolvimento de um referencial metodológico capaz de formular estratégias viabilizadoras dos objetivos de cada indivíduo.

\section{FundamentaÇão Teórica}

Para Kich e Pereira (2011, p. 16), o Planejamento Estratégico "[...] significa o caminho escolhido, as ações estabelecidas e adequadas para atingir os objetivos". Carvalho, Almeida e Wright (2008, p. 13) enfatizam a importância e a necessidade da existência de um Planejamento Estratégico Pessoal ao afirmarem que "[...] se a pessoa possui um claro objetivo pessoal, está dando significado e direção para sua vida". De acordo com Estrada, Pereira e Almeida (2007, p. 109), o Planejamento Estratégico

[...] consiste em uma técnica administrativa que procura ordenar as ideias das pessoas, de forma que seja possível criar uma visão do caminho 
que deve ser seguido (estratégia) e, também, ordenar as ações que serão realizadas através do plano estratégico, permitindo o alcance da visão de futuro.

Rios (2003, p. 628) define - em seu dicionário "rico" como aquele "[...] que possui muitos bens" e a "riqueza" como abundância, fartura. Nesta pesquisa "riqueza" será definida de outra maneira, não apenas em termos de posses materiais ou status, mas como investimentos, saúde, lazer, felicidade, acúmulo de bens valorizáveis, dinheiro, entre outros. Esse estudo é no mesmo sentido da frase de Chico Xavier que diz: "Um homem era tão pobre, mas tão pobre, que só tinha dinheiro". Ou seja, "riqueza" é muito mais do que dinheiro. De acordo com Santos e Almeida (2001), a "riqueza" pode ser formada pelo conhecimento, inovação e aprendizagem. Por outro lado, para Pastorino (1966) "[...] aquele que, mesmo pouco ou nada tendo, sabe doar-se em ajuda ao próximo, esse é rico, imensamente rico!". Além disso, Allen (1986, p. 4) considera que "[...] riqueza é quando esforços pequenos produzem grandes resultados. Pobreza é quando grandes esforços produzem resultados pequenos". Mesmo de pontos de vista diversos, pode-se perceber que esses autores consideram que alguém é de fato "rico" quando se sente bem, não necessariamente quando tem muito dinheiro.

No mesmo sentido, Neri (2008) afirma que existe uma correlação extremamente fraca entre renda, a variável mais venerada em economia, e a felicidade. Rodrigues e Shikida (2005) corroboram esse pensamento afirmando que não há uma relação explícita entre economia e felicidade. Para Martins (2010, p. 6) "[...] planejar é um instrumento de grande importância no estabelecimento do alcance dos objetivos". Enriquecer é um processo que leva tempo e deve ser constante, de modo que não se deve deixar iludir pelo status e/ou posse de bens materiais. Para àqueles que consideram o dinheiro sinônimo de "riqueza", uma estratégia para conquistar a "riqueza" é manter o dinheiro no banco rendendo juros, bem como investir em ações promissoras, que gerem lucro após certo prazo. Godfrey e Edwards (2007) sugerem que antes de ir às compras sejam feitos uma lista e um planejamento do que é preciso comprar.

Martins (2010) afirma que planejar é fazer uma "previsão" (do futuro desejado) e determinar os meios para alcançá-lo. Para algumas pessoas, planejar a própria vida pode parecer um exagero e, para outras, isso é uma necessidade. Planejar "[...] significa elaborar esquema para alcançar algo que se deseje, contrapondo-se à improvisação, que é ação ao acaso". (ESTRADA; PEREIRA; ALMEIDA, 2007, p. 107)

Segundo Martins (2010, p. 4), o planejamento pessoal

[...] implica em profunda reflexão pessoal sobre os valores e princípios, pontos diferenciais deficientes e competências especiais adquiridas. Esta ferramenta permite a visualização sistemática de onde se quer chegar, qual o caminho a seguir e qual o ponto de partida, o que também é importante.

Vale explicitar que, embora com objetivos bem definidos e convicção de onde (e quando) se quer chegar, o planejamento por si só não é garantia de que o indivíduo alcançará o desejado. É fundamental usar esse sentimento de segurança para criar e/ou aproveitar oportunidades e, ao mesmo tempo, estar atento às circunstâncias externas que fogem do controle e são imprevisíveis. Ao planejar, o indivíduo deve estar consciente dessa vulnerabilidade e esforçar-se o máximo possível na busca de alternativas e soluções para possíveis imprevistos. Além disso, no decorrer da vida é interessante reavaliar os próprios objetivos e fazer um realinhamento estratégico, preparando-se para lidar com as mais diversas situações. Deve-se ressaltar que não existe apenas um modelo de Planejamento Estratégico Pessoal, pelo contrário, ele precisa ser uma metodologia flexível, para estar de acordo com o modo de vida de cada pessoa, respeitando sua realidade, vontade e princípios/valores. Durante o planejamento, a pessoa posiciona-se em relação ao próprio futuro e deve, a partir de então, esforçar-se para alcançar suas metas, deixando de ficar à mercê da sorte ou do destino.

Planejar é um método eficaz para organizar-se e ter um controle dos próprios hábitos e gastos, permitindo, assim, que seus objetivos sejam alcançados. Esses planos podem ser de curto ou de longo prazo, dependendo da expectativa estabelecida e do desempenho alcançado até tal momento (COELHO, 2008). Ferreira et al. (2012, p. 54) explicam que "[...] as empresas que têm um rumo bem definido, com objetivos e metas claros, declarações de visão e missão e linhas 
de ação estabelecidas têm maior probabilidade de serem bem-sucedidas". O mesmo conceito vale para o Planejamento Estratégico Pessoal, de modo que o indivíduo que tem objetivos e metas, claros, e se organiza para realizar aquilo que foi previamente estabelecido, terá maiores chances de alcançar estabilidade. De acordo com Moritz, Moritz e Pereira (2012, p. 105), o planejamento objetiva a melhoria das decisões, bem como proporciona "ações para a construção de um futuro melhor".

Planejamento Estratégico é um processo que consiste na análise sistemática dos pontos fortes (competências) e fracos (incompetências ou possibilidades de melhorias) da organização, e das oportunidades e ameaças do ambiente externo, com o objetivo de formular (formar) estratégias e ações estratégicas com o intuito de aumentar a competitividade e seu grau de resolutividade. (PEREIRA, 2010, p. 47)

Os indivíduos podem se beneficiar muito do conhecimento de Planejamento Estratégico, antes aplicado somente nas organizações. Cumprir o planejado é seguir o caminho para alcançar o que se deseja. A partir do momento que o indivíduo estabelece metas e objetivos em seu Planejamento Estratégico Pessoal, passa a vê-los como um desafio a ser alcançado $e$, desse modo, sente-se mais motivado a realizá-lo (ULAF, 2002, p. 94 - 95). Para Serra (2007, p. 23), “[...] a estratégia também significa escolha. Essa escolha implica numa direção $e$, consequentemente, num rumo. Este rumo implica numa aposta, em um risco a ser assumido [...] para alcançar a recompensa desejada". Carvalho; Almeida e Wright (2008) ressaltam que o Planejamento Estratégico Pessoal deve ser refletido e atualizado de acordo com as necessidades e as mudanças ambientais ou de perspectivas do indivíduo. Similarmente, Oliveira (2009, p. 5) afirma que "[...] o planejamento está sempre vinculado a um período, e deve ser revisado periodicamente para que se mantenha em consonância com os anseios da pessoa". Kich e Pereira (2011, p. 270) ressaltam que o Planejamento Estratégico é um processo cíclico e sem fim, "[...] onde as pequenas batalhas vencidas devem ser valorizadas".

Similarmente ao estabelecido em uma empresa, o indivíduo deve estabelecer para si: valores, missão e visão. Normalmente, os valores compõem-se de regras morais que simbolizam os atos de seus fundadores.
Pereira (2010, p. 74) acredita que os valores "[...] são os balizadores da ação empresarial, eles dizem para todos na empresa o que é certo e o que é errado. São elementos nos quais os membros acreditam piamente". Os valores representam os princípios éticos que norteiam suas ações. A missão é a sua finalidade, está ligada aos seus objetivos institucionais, aos motivos pelos quais foi criada e representa a sua razão de ser. A missão é algo perene e sustentável, enquanto a visão é mutável, algo concreto a ser alcançado. A visão deve ser inspiradora, clara e concisa; é o sonho da organização, aquilo que espera ser num determinado tempo e espaço. É um plano, uma ideia mental que descreve o que a organização quer realizar em sua existência (SILVEIRA, 2010). Pereira (2010, p. 87) infere que a visão "[...] funciona como uma bússola, mostrando a direção na qual a organização está caminhando [...] e representa suas maiores esperanças e os seus mais expressivos sonhos".

Com valores, missão e visão definidos, fica claro o que determinada organização busca. Do mesmo modo, no âmbito particular a pessoa sente-se inspirada a seguir a direção programada e é encorajada a enfrentar desafios com determinação para alcançar seus objetivos. "Escrevendo sua missão pessoal, visão e objetivos, o indivíduo deixará suas idéias obrigatoriamente mais claras e concretas, aprendendo melhor para obter sucesso na implementação deste plano" (CARVALHO; ALMEIDA; WRIGHT, 2008, p. 14). A formulação da visão e missão pessoal significa que podem aparecer oportunidades para aprimorar comportamentos, visando o alcance dos objetivos e a realização das ações necessárias. Como "riqueza" não consiste apenas em dinheiro, cada um deve esforçar-se na busca daquilo que julga ser o melhor para si. Uma pessoa que considera a saúde como sua maior "riqueza", por exemplo, deve ter uma alimentação equilibrada, acompanhada de exercícios físicos para se manter sempre saudável. Aqueles que têm a família como sua maior felicidade e "riqueza", procuram passar o máximo de tempo possível na companhia de seus entes queridos, e, desse modo, consideram-se "ricos". É indispensável ter determinação para cumprir o orçamento, bem como para controlar as próprias ações relacionadas a compras por impulso. Estar atento a ofertas, promoções, pechinchar, pesquisar preços e negociar faz parte da rotina de muitos acumuladores de "riqueza". Godfrey 
e Edwards (2007) também acreditam que pesquisar, planejar, fazer orçamento e ter disciplina são aspectos fundamentais para fazer o dinheiro render.

Souza (2004) corrobora a necessidade de possuir um orçamento e propõe algumas diretrizes para segui-lo. Segundo ele, deve-se utilizar dinheiro somente naquilo que realmente satisfaz uma necessidade; manter aquilo que já foi comprado, para que não seja preciso gastar dinheiro outra vez com a mesma coisa; estabelecer prioridades para as decisões de uso do orçamento; além de conhecer as alternativas de preço $e$ vantagens em cada serviço ou produto a ser adquirido. Cerbasi (2009) concorda que manter o equilíbrio orçamentário é fundamental. Augustin (2008, p. 81) infere que o plano orçamentário é um instrumento de controle "[...] importante para a vida da pessoa, pois diz respeito ao que ela tem ou deseja ter". Muitas vezes, a "riqueza" pode estar ligada a sentimentos de realização e satisfação, então, pode ter grande valor para um indivíduo o fato de ele ser autossuficiente financeiramente. De acordo com Carvalho, Almeida e Wright (2008), uma das maiores dificuldades encontradas pelos consumistas ao tentarem obter sucesso econômico é sua insaciável vontade de satisfazer desejos de curto prazo, negligenciando, desse modo, o próprio planejamento. Perseverar é o modo mais eficiente de atingir objetivos. Destarte, pode-se dizer que o indivíduo capaz de guardar parte do seu salário adquirirá mais, em longo prazo, do que o indivíduo que ganha bem, porém, gasta tudo (PRIMON, 2011). O mesmo pode acontecer com alguém que tem saúde, mas não zela por ela, num dado momento, pode o organismo sentir-se prejudicado e apresentar sinais de doença ou cansaço.

\section{Metodologia: A trajetória da PESQUISA}

Inicialmente, para o desenvolvimento da análise, fez-se uma pesquisa por artigos científicos disponíveis nos principais indexadores da área de Administração do Portal Brasileiro da Informação Científica - periódicos da CAPES, fazendo uma busca avançada por "Planejamento Estratégico Pessoal". Também foram utilizados livros, dissertações e teses referentes ao assunto. Desse modo, foram obtidos os dados secundários e a fundamentação teórica da presente pesquisa. Com base na revisão teórica, elaborou-se um questionário para servir de instrumento de coleta de dados. O instrumento configurou-se em 35 questões fechadas. Para facilitar o envio do instrumento, utilizou-se a tecnologia "Google docs formulários" desenvolvida pelo Google ${ }^{\circledR}$. Essa tecnologia permitiu a geração de um link, que pôde ser enviado de forma on-line e visou reduzir ao máximo o tempo que o respondente gastaria para responder à pesquisa. Desse modo, a coleta dos dados primários deu-se através da aplicação deste questionário.

Após a primeira versão, o questionário passou por uma fase de pré-teste para correção de eventuais inconsistências e nova elaboração e adequação das questões. O pré-teste foi feito com seis respondentes, sendo um professor da disciplina de Administração da Produção (UNIPAMPA - Universidade Federal do Pampa), um doutorando em Administração da UFSC, uma mestranda em Administração da UFSC e três graduandos, sendo um em Engenharia Civil ( $7^{\mathrm{a}}$ fase - UFSC); e duas em Administração (5 $5^{\text {a }}$ fase - UFSC). As considerações feitas durante a fase de pré-teste motivaram alterações, como a adequação das instruções referentes ao preenchimento das questões, que foram devidamente modificadas. A partir de então, o questionário foi disponibilizado aos respondentes.

Inicialmente, fez-se uma tentativa de enviá-lo através do e-mail oficial cadastrado no Núcleo de Processamento de Dados (NPD) da UFSC, pois o universo da pesquisa, ou público pesquisado, seriam todos os alunos, professores e servidores da UFSC. Após contato inicial com o NPD, descobriu-se que esse órgão não envia questionários de pesquisas acadêmicas, pois tem fins informativos apenas. Então, solicitou-se a divulgação do questionário no site da Agecom (Agência de Comunicação da UFSC). O pedido foi atendido prontamente e o questionário foi divulgado na primeira página do site da UFSC (www. ufsc.br) e também no site da Agecom (http://noticias. ufsc.br/2012/03/30/planejamento-estrategico-pessoal-questionario/), ambos no dia 30 de março de 2012.

O questionário on-line esteve disponível no período entre 30 de março de 2012 e 19 de maio de 2012. Optou-se por aplicar o questionário de forma individual e estruturada, numa pesquisa exploratória, na qual os respondentes posicionaram-se de acordo 
com sua própria realidade e experiência. Vale ressaltar que a pesquisa foi anônima, ou seja, ninguém escreveu o nome no questionário, garantindo assim o sigilo do levantamento e a autenticidade das respostas. Ao todo, 345 pessoas responderam ao questionário. Embora tenha sido divulgado em dois sites muito visitados, não é possível afirmar quantas pessoas efetivamente tiveram acesso ao questionário. A fase final consistiu na tabulação, análise e interpretação dos dados.

\section{Análise e Discussão dos Dados}

A fim de conhecer o perfil dos respondentes dessa pesquisa, foram feitas a eles perguntas a respeito de gênero, idade e escolaridade. Em relação ao gênero, a maioria dos participantes dessa pesquisa constitui-se de pessoas do gênero feminino. Dos 345 respondentes, 197 são do gênero feminino, número que corresponde a $57 \%$ do total. Os demais 148 participantes - o equivalente a $43 \%$ - são do gênero masculino. A maioria tem mais de 36 anos, pois $37 \%$ dos participantes escolheram essa alternativa ao serem questionados a respeito da própria idade - esse número corresponde a 126 respostas. O equivalente a $14 \%$ do total, ou seja, exatamente 47 pessoas têm entre 31 e 35 anos; $15 \%$ dos respondentes têm entre 26 e 30 anos, uma vez que foram obtidas 53 respostas com essa alternativa. Além disso, $21 \%$ dos participantes têm de 21 a 25 anos (72 pessoas). Houve 42 respostas com idade de 15 a 20 anos (12\% dos respondentes). Cinco pessoas não responderam a essa questão ( $1 \%$ dos participantes).

Buscou-se saber qual seria o nível de escolaridade dos participantes dessa pesquisa. Desse modo, constatou-se que 30 pessoas possuem Ensino médio completo, o que corresponde a $9 \%$ do total. A maioria dos participantes possui Graduação, uma vez que 39\% dos respondentes - 136 pessoas - encontram-se nessa posição. $13 \%$ dos respondentes fizeram Especialização, número equivalente a 46 participantes. Além disso, 56 pessoas possuem Mestrado, representando $16 \%$ dos respondentes. Doutorado foi o segundo nível de instrução mais respondido, com $20 \%$ do total, porcentagem equivalente a 70 respondentes com essa formação. Finalmente, $2 \%$ responderam que possuem outro nível de escolaridade, sendo esse percentual representado por sete respondentes. Destes sete, cinco possuem
Graduação em andamento, um está fazendo Mestrado e o último possui Pós-doutorado.

Solicitou-se que os respondentes escolhessem uma alternativa para definir o significado de "riqueza" para ele mesmo. As respostas poderiam ser: ter saúde, ter sucesso, ter felicidade, possuir bens materiais, ter muito dinheiro para investir, ter muito dinheiro para gastar ou, caso não se enquadrasse em nenhuma dessas, poderia escolher a opção "outros". Dos 345 respondentes, 85 pessoas escolheram "ter saúde" como sua maior "riqueza". Esse número representa um quarto do total, ou seja, $25 \%$ dos respondentes. Além disso, $28 \%$ das respostas posicionaram-se no sentido de que "ter felicidade" seria a melhor definição $\mathrm{de}$ "riqueza". Esse percentual equivale a 96 pessoas, que pode ser considerado um número significativo de respondentes. Essas duas categorias (ter saúde e ter felicidade) juntas representam mais da metade das respostas, ou seja, para $53 \%$ dos entrevistados, ter "riqueza" é ser saudável e/ou feliz.

Ainda nessa mesma questão, $14 \%$ dos respondentes consideram "ter sucesso", como sua "riqueza", com o número de 48 respostas. Além disso, "possuir bens materiais" (17 respostas), "ter muito dinheiro para gastar" (39 respostas) e "ter muito dinheiro para investir" (18 respostas) ocupam, respectivamente, $5 \%$, $11 \%$ e $5 \%$ do total. Juntas essas três categorias que envolvem dinheiro representam $21 \%$ das respostas, portanto, a maioria dos respondentes dessa pesquisa não considera que a "riqueza" esteja necessariamente ligada ao dinheiro. Quanto aos demais 42 respondentes, que equivalem à categoria "outros", com $12 \%$ do total, têm posicionamentos variados a respeito de "riqueza". Seis dessas respostas foram "todas as alternativas", com comentários sobre ter saúde e pessoas queridas por perto, além de possuir a prosperidade material, sendo que gastar pode ser considerado um investimento, bem como a soma de alternativas anteriores (relativamente), incluindo amor e paz de espírito. Para dois respondentes, a "riqueza" é um conjunto de bens materiais e sociais/ imateriais. Para outro é ter estabilidade financeira (renda mensal de aluguéis ou outras fontes) para poder trabalhar naquilo que gosta. Houve ainda um respondente que se posicionou no sentido de que é preciso "[...] muito dinheiro para ter saúde. Claro que isso na sociedade em que vivemos. Se fosse no meio do mato isolado não precisaria de di- 
nheiro e ter-se-ia saúde boa". Cinco pessoas afirmaram que sua "riqueza" corresponde à fé; estar com Deus $e$, consequentemente, com a felicidade; bem como ter salvação em Cristo Jesus. No mesmo sentido, um respondente afirma que ter alto nível de satisfação com as áreas da "Roda da Vida" é ter "riqueza". Além disso, quatro respondentes consideram a família seu maior tesouro, no sentido de ter uma família maravilhosa com saúde e harmônica.

Para outras quatro pessoas, gostar de si próprio; olhar no espelho e gostar do que vê; ter satisfação pessoal e/ou gostar do que faz é sua "riqueza". Por outro lado, cinco respondentes consideram a paz de espírito/ paz interior; viver com equilibrio e tranquilidade; ter bem-estar espiritual e físico e/ou se sentir bem sua "riqueza" pessoal. Para três pessoas, se sentir útil no meio em que vive, ou relaciona-se; ter princípios, moral, educação, respeito e ser um homem de bem é considerado "riqueza". Um respondente afirmou que ter acesso faria-lhe sentir-se "rico". E outro, ter amplo conhecimento. Em contrapartida, dois respondentes mostraram-se consumistas/materialistas ao afirmarem que "riqueza" para eles é ter dinheiro para investir e gastar sem preocupação com limites, bem como ter muito dinheiro para viajar. Finalmente, duas pessoas gostariam de ter saúde, sucesso, felicidade, autorrealização e dinheiro suficiente. Similarmente, outras três sentir-se-iam ricas caso tivessem qualidade de vida e/ ou investissem na saúde. Um último respondente corrobora com essas três, pois, para ele, "riqueza" seria ter tempo para se dedicar à saúde mental. Interessante e inusitado o fato de apenas $21 \%$ do total de respondentes considerarem que a "riqueza" está relacionada ao dinheiro. Do mesmo modo, os autores Santos e Almeida (2001), Rodrigues e Shikida (2005), Pastorino (1966), Allen (1986) e Neri (2008) definem a "riqueza" de diversas formas, que não significam possuir dinheiro e/ou bens materiais. Ou seja, as respostas obtidas com a aplicação do questionário vão ao encontro do que consta na literatura a respeito de "riqueza".

Considerando que existem outras maneiras para se formular as estratégias pessoais, ainda que não sejam denominadas Planejamento Estratégico Pessoal (ESTRADA; MORETTO NETO; AUGUSTIN, 2011), buscou-se identificar o perfil das pessoas que de alguma forma planejam seu futuro. A presente pesquisa aponta que $75 \%$ dos respondentes fazem orçamentos para todos os itens de compra. Quanto aos outros $25 \%$ que não fazem qualquer forma de orçamento, sugere-se que criem o hábito de orçar, pois o orçamento pode ser uma ótima ferramenta de controle para avaliar os gastos reais em comparação com os gastos previstos para determinado período (CERBASI, 2009; AUGUSTIN, 2008; GODFREY; EDWARDS, 2007; SOUZA, 2004; STANLEY; DANKO, 1999). Fazendo-se o cruzamento entre a quantidade de respondentes que fazem orçamento e o gênero de cada um, é interessante que, apesar de a maioria ser do gênero feminino, os homens costumam fazer mais orçamento do que as mulheres. Dos 148 homens que responderam à pesquisa, 93\% afirmam fazer orçamentos. Quanto às 197 mulheres que responderam ao questionário, $86 \%$ fazem orçamentos, porcentagem equivalente a 170 respondentes do gênero feminino. Com base nessas informações pode-se dizer que os respondentes do gênero masculino orçam mais do que os do gênero feminino.

Relacionando as respostas daqueles que fazem orçamento com a idade, nota-se que $86 \%$ dos respondentes (36 de 42 pessoas) que têm de 15 a 20 anos fazem orçamento. $94 \%$ dos participantes dessa pesquisa com idade de 21 a 25 anos também orçam, sendo esse percentual representativo de 68 dos 72 respondentes dessa categoria. Além disso, $92 \%$ das pessoas que têm idade entre 26 e 30 anos são orçamentistas, tendo 49 pessoas nessa posição. Em seguida, 43 pessoas, que representam $91 \%$ dos 47 respondentes que têm entre 31 e 35 anos fazem orçamentos. Além disso, $90 \%$ dos respondentes que têm mais de 36 anos costumam orçar, o que equivale a 114 dos 126 respondentes dessa categoria. Pode-se afirmar, com base nos dados, que não há correlação entre a idade de alguém e o hábito de fazer orçamentos, pois há pouca variação entre o número de orçamentistas em cada faixa etária.

A seguir discute-se a relação entre o nível de escolaridade dos respondentes e o hábito de fazer orçamento, de acordo com as informações obtidas com a aplicação do questionário. Desse modo, constatou-se que 27 dos 30 respondentes que possuem Ensino médio fazem orçamentos, o que equivale a $90 \%$ do total. Quanto aos 136 respondentes graduados, 119 orçam, o que corresponde a $88 \% .87 \%$ das pessoas que possuem Especialização são orçamentistas, percentual que representa 40 respondentes. Além disso, 95\% das 
pessoas que têm Mestrado orçam, o que equivale a 53 pessoas. Finalmente, 64 dos 70 respondentes que possuem Doutorado fazem orçamentos, correspondendo a $91 \%$ do total dessa categoria. Com base nessas informações pode-se dizer que o nível de escolaridade não influencia na decisão dos participantes dessa pesquisa orçarem ou não, pois o nível de orçamento está equilibrado entre os níveis de instrução.

Em relação às pessoas que afirmaram fazer orçamentos, 26 pessoas (10\% dos 258 respondentes que realizam o orçamento) o realizam anualmente. Outras 189 pessoas fazem orçamento mensal, sendo essa a forma predominante, com $73 \%$ do total. Além disso, 23 pessoas fazem orçamento semanal, equivalendo a $9 \%$ dos orçamentistas. E, finalmente, 13 pessoas realizam orçamentos diariamente, representando $5 \%$ do total. É ínfima a quantidade - apenas 3\% - de orçamentistas que se enquadraram na categoria "outros". Dessas sete pessoas, quatro realizam seu orçamento de forma "desorganizada", dependendo do que está sendo pesquisado, ou de acordo com os objetivos de aquisição/ importância. Um deles realiza o orçamento trimestralmente, enquanto outros dois fazem-no tanto mensal quanto anualmente. De acordo com Cerbasi (2009), Augustin (2008), Godfrey e Edwards (2007), Souza (2004) e Stanley e Danko (1999), orçar é indispensável para a organização, controle e sucesso pessoal, porém os autores não especificam qual seria o intervalo recomentado para a realização desse orçamento, até porque, esse intervalo tende a estar relacionado com a periodicidade que determinada pessoa recebe sua renda.

Especificamente quanto ao planejamento pessoal, dos 345 respondentes, 258 responderam positivamente, ainda que não seja necessariamente através de um modelo de Planejamento Estratégico Pessoal. Esse número de respostas "sim" equivale a $75 \%$ do total. Os $25 \%$ demais, que correspondem a 87 respondentes, não fazem nenhuma forma de planejamento de vida. É recomendável que as pessoas planejem-se, podendo, dessa forma, ter uma vida mais organizada e produtiva, além de aproveitarem melhor seu tempo, saúde, dinheiro, entre outros. Segundo Oliveira (2009), Kich e Pereira (2011), Carvalho, Almeida e Wright (2008), Estrada, Pereira e Almeida (2007); Augustin (2008), Vasconcelos (2010), Ulaf (2002), Estrada, Flores e Schimith (2011), Martins (2010), Stanley e Danko (1999),
Godfrey e Edwards (2007), Coelho (2008) e Cerbasi (2009), o planejamento auxilia no bom desempenho não apenas da vida financeira dos indivíduos, mas em aspectos gerais.

Como foi constatado que a "riqueza" não significa apenas possuir dinheiro, pode-se afirmar que o planejamento é indispensável para que as pessoas sintam-se realizada. Do mesmo modo como se buscou saber se havia alguma relação entre gênero, idade ou escolaridade dos respondentes e o fato de os mesmos fazerem ou não orçamentos, nessa etapa faz-se o cruzamento entre o gênero das pessoas e o fato de fazerem ou não algum planejamento pessoal. 148 dos 197 respondentes do gênero feminino afirmam fazer algum planejamento, o que corresponde a $75 \%$ dos respondentes dessa categoria. Além disso, dos 148 respondentes do gênero masculino, 111 possuem algum planejamento, número equivalente a $75 \%$ do total do gênero masculino. Como $75 \%$ dos respondentes de ambos os gêneros afirmam fazer orçamentos, pode-se afirmar que o gênero da pessoa não interfere no fato de ela planejar-se ou não.

O próximo passo foi identificar se havia ou não alguma relação entre a idade dos respondentes e o fato de eles possuírem ou não planejamento; 42 respondentes têm idade de 15 a 20 anos, e destes, 36 fazem planejamento, equivalendo a $86 \%$ do total dessa categoria. Quanto aos 72 respondentes que têm de 21 a 25 anos, 56 planejam-se, o que corresponde a $78 \%$ dos respondentes nessa faixa etária. Dos 53 respondentes que têm entre 26 e 30 anos, 48 consumam planejar, sendo esta a faixa etária com maior percentual de planejadores, com $91 \%$ do total. 47 respondentes têm entre 31 e 35 anos, sendo que destes, 35 fazem planejamento, correspondendo a $74 \%$ dos respondentes deste patamar. Finalmente, 86 dos 126 respondentes que têm mais de 36 anos planejam-se, o que equivale a $68 \%$ dos respondentes desta faixa etária. Os respondentes com mais de 36 anos são os que menos planejam dentre os participantes dessa pesquisa. A princípio pode-se dizer que há pouca relação entre a idade dos respondentes e o fato de fazerem planejamentos, pois há pouca variação entre as porcentagens de cada faixa etária. Porém, nota-se que os respondentes entre 31 e 35 anos e aqueles com mais de 36 tendem a planejar menos do que os indivíduos que têm de 26 a 30 anos. 
Especulou-se também se existiria alguma relação entre o nível de escolaridade e o planejamento dos respondentes. Constatou-se que dos 30 respondentes que possuem Ensino médio, 23 planejam, o que equivale a $77 \%$ do total dessa categoria. A respeito dos 136 respondentes que têm Graduação, 99 planejam, correspondendo a $73 \%$ do total de graduados. 36 dos 46 respondentes que possuem Especialização fazem planejamento, representando $78 \%$ desses participantes. Além disso, 89\% dos respondentes que têm Mestrado são planejadores, sendo que 50 dos 56 respondentes dessa categoria responderam positivamente à questão de planejamento. Finalmente, dentre os 70 respondentes que possuem Doutorado, 48 planejam-se, número equivalente a $69 \%$ desses respondentes. Ao observar os dados apresentados, nota-se que não há correlação entre o nível de escolaridade e o fato de planejar, pois apesar de os respondentes que têm Mestrado serem os mais planejadores, com $89 \%$, os que possuem Doutorado são os menos planejadores, uma vez que planejam $20 \%$ menos do que os mestres - apenas 69\%. Interessante que essa diferença maior é notada justamente entre as duas categorias com nível de escolaridade superior.

Dos 258 participantes que realizam planejamento de vida, 162 fazem-no anualmente, esse número corresponde a $63 \%$ das respostas, ou seja, mais da metade dos respondentes planeja-se a intervalos anuais. Além disso, $16 \%$ dos entrevistados (41 pessoas) fazem planejamentos com períodos mensais. Há, ainda, o planejamento semanal, realizado por 19 respondentes, que representam $7 \%$ do total. Finalmente, o planejamento diário é realizado por 29 pessoas, que correspondem a $11 \%$ dos respondentes. Sete pessoas deixaram essa questão sem resposta, ou seja, $3 \%$ dos 258 respondentes não especificaram se realizam seu planejamento anual, mensal, semanal ou diariamente.

De acordo com Oliveira (2009), Kich e Pereira (2011), Carvalho, Almeida e Wright (2008), Estrada, Pereira e Almeida (2007), Augustin (2008), Vasconcelos (2010) Ulaf (2002), Estrada, Flores e Schimith (2011), Martins (2010), Stanley e Danko (1999) Godfrey e Edwards (2007), Coelho (2008) e Cerbasi (2009), o planejamento é sempre recomendado na busca de melhor desempenho. Os autores não se posicionam no sentido de qual seria o período ideal para o planejamento, mas nota-se que todos concordam que é fundamental ter metas e que os planos podem ser de curto ou de longo prazo, dependendo da expectativa estabelecida e do desempenho alcançado até tal momento.

Dos 345 respondentes, 267 têm seus objetivos definidos. Esse número equivale a $77 \%$ do total. 78 pessoas afirmam não ter seus objetivos definidos, ou seja, $23 \%$ dos participantes dessa pesquisa não definiram, ainda, nenhuma meta para sua vida. Conforme aponta a literatura da área, ter claros seus objetivos e metas pode auxiliar as pessoas no desempenho de suas atividades, selecionando aquilo que realmente é de seu interesse, otimizando processos e reduzindo o desperdício de recursos em geral, principalmente tempo e energia. Vale ressaltar que estabelecer objetivos é uma etapa importante no processo de planejamento (OLIVEIRA, 2009; CARVALHO; ALMEIDA; WRIGHT, 2008; ULAF, 2002; MARTINS, 2010; STANLEY; DANKO, 1999; COELHO, 2008; CERBASI, 2009). Apesar de muitos não terem seus objetivos definidos, acredita-se que a grande maioria dos respondentes trabalha, uma vez que os respondentes são alunos (podendo ser bolsistas/ estagiários), professores e servidores da UFSC. Destarte, perguntou-se o que lhes motiva a trabalhar. Constatou-se que 135 entrevistados trabalham por prazer, o que corresponde a $39 \%$ do total. Apenas oito pessoas trabalham por ganância, representando $2 \%$ dos entrevistados. É ínfima a participação de indivíduos que trabalham apenas para pagar dívidas, uma vez que apenas um respondente encontra-se nessa posição. Porém, 149 participantes dessa pesquisa afirmam trabalhar por necessidade, equivalendo a $43 \%$ do total.

Os demais $15 \%$ encontram-se na posição "outros". Esses 52 respondentes tiveram posicionamentos bem variados. Dois respondentes não trabalham. Outros três trabalham por necessidade aliada a outros fatores, como crescimento pessoal, busca por realização pessoal e profissional, necessidades financeiras; de realização; de sentir-se útil, entre outros. Sete consideram prazer e necessidade igualmente motivadores. Outro entrevistado considera a satisfação $e$ a necessidade seus fatores motivacionais. Além disso, dois buscam a satisfação pessoal. Para outra pessoa, a motivação se dá por um misto de prazer, necessidade e status. Outros dois participantes trabalham por prazer, um deles explicita seu prazer aliado a bolsas de pesquisa 
e extensão enquanto outro trabalha por prazer e dinheiro. Um respondente considera todas as alternativas importantes. Outro participante da pesquisa diz que trabalhar é ruim, mas não trabalhar é pior. Por outro lado, uma pessoa diz amar o que faz e outra possui muita afinidade com a própria função. Cinco entrevistados buscam a realização, não só de conquistas, mas também a realização pessoal e profissional. Três respostas foram no sentido de suprir desejos de crescimento pessoal e possuir uma identidade.

Do total de respondentes, 11 pessoas mostram-se mais altruístas, pois três participantes trabalham pela família enquanto outro trabalha pela escolaridade dos filhos. Atribuem ao trabalho certo senso de responsabilidade. Nesse sentido, quatro ficam felizes por saberem que o que fazem está beneficiando uma coletividade, em trabalhos que trazem resultados sociais e conseguem cumprir sua missão no mundo, bem como realizar seus objetivos de vida. Um entrevistado diz ficar satisfeito ao ver o resultado do trabalho. Uma pessoa considera o trabalho importante para manter a qualidade de vida e outro respondente busca unir o útil ao agradável. Um entrevistado respondeu que trabalha simplesmente para ter o que fazer. Por outro lado, dois querem ter sucesso e crescimento profissional. Duas pessoas buscam conhecimento e experiência. Um respondente trabalha por ambição e outro por competição. Uma pessoa afirma que quem não trabalha fica doente e, a outra se sente bem ao relacionar-se com colegas de trabalho, além disso, trabalha por dinheiro. Finalmente, um participante da pesquisa afirmou que trabalha a fim de juntar o dinheiro necessário para investir numa mudança de carreira.

De acordo com os dados, pode-se perceber que parte dos respondentes trabalha porque precisa de dinheiro, enquanto outros buscam satisfazer-se e ajudar os demais. As duas opções predominantes foram prazer e necessidade, com $39 \%$ e $43 \%$, respectivamente. Trabalho, persistência e determinação auxiliam para que as pessoas alcancem o sucesso que almejam (STANLEY; DANKO, 1999; MARTINS, 2010; CALVOSA, 2011; CERBASI, 2009; GODFREY; EDWARDS, 2007). Perguntou-se aos participantes o que eles fazem com o dinheiro; 45 pessoas responderam que investem, o que corresponde a $13 \%$ dos entrevistados. 41 pessoas gastam seu dinheiro em lazer, o que representa $12 \%$ do total de respondentes. Além disso, $8 \%$ (27 pessoas) compram tudo o que têm vontade. Por outro lado, 163 pessoas - que equivalem a $47 \%$ dos respondentes compram apenas o necessário, ou seja, quase a metade dos participantes da pesquisa evita comprar coisas que sejam dispensáveis. Os demais 69 respondentes encontram-se na posição "outros", correspondendo a $20 \%$ do total de entrevistados.

Dos 69 entrevistados que escolheram a opção "outros", um não trabalha. Três afirmaram que apenas sobrevivem com o dinheiro que ganham e outros dois responderam que só dá para viver. No mesmo sentido, cinco indivíduos usam seu dinheiro para pagar as contas/ despesas. Houve três respostas relacionadas ao suprimento de necessidades, bem como necessidades e lazer. Duas pessoas dão preferência a investimentos e lazer; 31 participantes dessa pesquisa responderam que dividem seus gastos entre "vários itens" ou "com todas as alternativas", sendo "um pouco de cada coisa". Alguns especificaram que pagam contas, muitos impostos, compram o necessário e economizam um pouco por mês, mas sem deixar de gastar com viagens e festas. Ou seja, esses respondentes gastam seu dinheiro com diversos produtos e serviços simultaneamente. Uma pessoa explicou que nem sempre sobra para fazer investimentos, mas quando tem uma "sobrinha", sempre guarda. Três entrevistados gastam seu dinheiro com despesas domésticas (água/ luz/ escola) e lazer; e outro com despesas básicas (alimentação, vestuário, filhos). Dois respondentes administram suas vidas em busca dos objetivos planejados. Uma pessoa afirma pagar contas e investir na mudança de carreira, basicamente.

Um respondente afirma aplicar na poupança $e$ outro apenas guarda o dinheiro que tem. Dois participantes dessa pesquisa gastam com qualidade de vida e, similarmente, uma pessoa procura ter uma vida confortável. Um entrevistado investe em qualidade de vida, escola, alimentação e bem estar da própria família. Além disso, três entrevistados pagam todas as contas fixas mensais e poupam o que resta, gastando parte dessa quantia com lazer e investindo com o que sobra. Quatro pessoas mostraram-se preocupadas com a educação, pois uma adquire livros com o dinheiro que possui, outra investe na própria escolaridade e, finalmente, dois respondentes investem na educação dos filhos. Outro diz apenas sustentar a família. O último respondente afirma que gasta seu dinheiro com o próprio conforto e ajuda os mais necessitados. 
Como $47 \%$ dos respondentes compram apenas o necessário, significa que quase metade dos entrevistados está preocupada em adquirir estabilidade financeira. Aos demais $53 \%$, recomenda-se que, caso anseiem ter dinheiro, adotem hábitos mais econômicos, de modo que reste algum dinheiro disponível. Fazer orçamentos, pesquisas e planejar o que comprar pode ser uma boa estratégia para começar a poupar dinheiro. Nota-se que alguns respondentes já possuem planejamento, pois, afirmaram tentar cumpri-lo.

Como três respondentes afirmaram que apenas sobrevivem com o dinheiro que ganham e outros dois responderam que apenas dá para viver, sugere-se que, nesse caso, o objetivo dessas pessoas seja acumular bens materiais, portanto, eles não deveriam gastar tudo que recebem, buscando sempre poupar. É essencial identificar as reais necessidades de consumir e entender a diferença entre querer e precisar (STANLEY; DANKO, 1999; MARTINS, 2010; CALVOSA, 2011; CERBASI, 2009; GODFREY; EDWARDS, 2007). Nota-se que a resposta que predominou foi "compra apenas o necessário", com $47 \%$ das respostas, ou seja, parece que quase metade dos respondentes busca poupar algum dinheiro, conforme é orientado pelos autores. Além disso, não há grandes diferenças de porcentagens entre as demais alternativas - gasta com lazer: $12 \%$; faz investimentos: $13 \%$ e compra tudo o que tem vontade: $8 \%$.

Buscando conhecer quanto os respondentes preocupam-se com seu status ou situação financeira futura, perguntou-se aos respondentes qual o critério utilizado na escolha da própria carreira. A maioria dos respondentes afirma ter escolhido essa carreira por afinidade, pois $77 \%$ dos 345 respondentes encontram-se nessa posição, o que corresponde a 265 pessoas. A necessidade foi o motivo pelo qual 47 pessoas escolheram sua profissão, representando $14 \%$ do total. É ínfima a representatividade da escolha por ganância, que foi de apenas duas pessoas, o equivalente a $1 \%$ dos respondentes. Foi ínfima também a escolha baseada em status, pois somente seis pessoas usaram esse critério na escolha de sua carreira, representando $2 \%$ dos respondentes. Finalmente, 25 pessoas encontram-se na posição "outros", número equivalente a $7 \%$ do total de entrevistados. Desses 25 respondentes, quatro não sabem por que escolheram essa profissão e outro não trabalha. Quatro pessoas optaram por essa carreira porque esse era seu maior sonho. Um respondente afirma que a responsabilidade foi o que determinou sua escolha e outro a estabilidade.

Para uma pessoa, essa carreira era seu propósito. Três participantes dessa pesquisa justificam sua escolha de carreira pela oportunidade ou falta de opção. Quatro pessoas estão nessa carreira por afinidade aliada à necessidade e ganhos. Dois explicaram que as circunstâncias da vida levaram-nos à carreira, não foi exatamente uma escolha. Por outro lado, um respondente escolheu a profissão devido às aptidões mentais para as áreas exatas. Um respondente buscava a realização e outro o idealismo, enquanto o último queria aliar realização pessoal e profissional. Com base nos dados, pode-se perceber que a maioria dos respondentes escolheu sua carreira por afinidade, sendo essa a posição de $77 \%$ do total de respondentes. Além disso, não há grandes diferenças de porcentagens entre as demais alternativas, sendo necessidade a segunda colocada, com $14 \%$. Como a maioria dos respondentes dessa pesquisa não considera que a "riqueza" esteja necessariamente relacionada ao dinheiro, podendo ter significados diversos, pode-se perceber, mais uma vez, que é ínfima a quantidade de pessoas que priorizaram a questão financeira na escolha de sua carreira. (SANTOS; ALMEIDA, 2001; RODRIGUES; SHIKIDA, 2005; PASTORINO, 1966; ALLEN, 1986; NERI, 2008)

Especulou-se o que os respondentes fariam caso ganhassem $\mathrm{R} \$ 100.000,00$ naquele momento. Dos 345 respondentes, 11 afirmaram que comprariam um carro, sendo esse número equivalente a $3 \%$ do total. $45 \%$ do total pouparia esse dinheiro, sendo essa a opção com maior número de respondentes: 155 participantes poupariam. Apenas 15 pessoas gastariam esse valor em lazer, o equivalente a $4 \%$ do total. 89 respondentes - $26 \%$ do total - comprariam uma casa. 75 pessoas escolheram a opção "outros", ou seja, $22 \%$ dos respondentes faria algo diferente com esse dinheiro.

Desses 75 respondentes que escolheram a opção "outros", dois não sabem o que fariam com esse dinheiro, mas 22 participantes dessa pesquisa investiriam essa quantia (em imóveis, negócio atual, nova carreira, entre outros), e outro aplicaria em ações para tentar multiplicar o valor no curto prazo. Nove pessoas pagariam todas as dívidas e três poupariam o que sobrasse depois de quitar as dívidas. Quatro 
respondentes usariam esse dinheiro para viajar, um deles usaria para estudar. Outro compraria um carro $e$ faria viagens. Oito pessoas usariam o dinheiro em todas as opções citadas, como "[...] dar entrada em um imóvel, talvez um carro popular e guardar uma considerável quantia". Um participante compraria terreno e outro compraria uma moto. Dois respondentes gastariam uma parte e poupariam o resto, enquanto outro guardaria toda a quantia. Uma pessoa pouparia a maior parte, mas aproveitaria para comprar um apartamento. Outro respondente daria entrada em dois apartamentos, financiaria a diferença e pagaria como se fosse o aluguel dos imóveis. Um respondente montaria sua própria empresa enquanto outro venderia o imóvel que possui e juntaria o dinheiro da venda com esses $\mathrm{R} \$ 100.000,00$ para comprar um imóvel melhor. Um participante faria uma biblioteca em casa e outro gastaria em lazer e pouparia. Duas pessoas analisariam as necessidades antes de gastar o dinheiro. Sete respondentes mostraram-se interessados em ajudar os demais, sendo que um iniciaria uma clínica para a própria filha, enquanto outro daria um ensino melhor para a filha, quatro ajudariam familiares e um faria uma manutenção na casa da mãe. Duas pessoas fariam uma reforma na própria casa e poupariam o restante. Uma pessoa investiria $90 \%$ e o restante utilizaria para uma viagem a lazer. Um respondente usaria a metade para construir um chalet numa chácara no interior e a outra metade usaria para viajar ao seu país de origem. Finalmente, um respondente construiria uma casa de praia, pois já tem o terreno.

Com base nos dados pode-se perceber que quase metade dos respondentes $(45 \%)$ preferem poupar esse dinheiro ao invés de gastá-lo em algo que não estão precisando no momento; $26 \%$ dos respondentes comprariam uma casa, sendo essa uma necessidade primordial. Dentre os $22 \%$ que responderam "outros", é notável que a maioria também escolheu gastos com investimentos, aquisição de imóveis, pagamento de dívidas ou abertura de novos negócios, a fim de evitar os gastos com aluguel, além de garantir alguma fonte de renda. Desse modo, pode-se afirmar que parte considerável dos respondentes está no caminho certo caso pretendam acumular dinheiro, pois evitam gastos desnecessários e desperdícios. (CERBASI, 2009; GODFREY E EDWARDS, 2007; SOUZA, 2004; STANLEY; DANKO, 1999)

\section{Considerações Finais}

Da mesma forma que ocorre em uma organização, sugere-se neste trabalho a possibilidade de se estabelecer um plano de vida. Esses planos podem ser de curto ou de longo prazo, dependendo da expectativa estabelecida e do desempenho alcançado até tal momento (COELHO, 2008). Os autores apresentados nessa pesquisa descrevem o Planejamento Estratégico Pessoal e concordam que o mesmo é relevante e necessário para que as pessoas alcancem seus objetivos, que podem se distinguir de pessoa para pessoa. Essa prerrogativa também consta nos elementos empíricos da pesquisa, uma vez que a maioria dos respondentes considera o planejamento importante para alcançar seus objetivos tanto no âmbito pessoal quanto profissional.

Diante desse panorama, entende-se que compreender o perfil das pessoas que utilizam alguma forma de planejamento pessoal torna-se uma premissa fundamental para o desenvolvimento de um referencial metodológico de Planejamento Estratégico Pessoal consistente e de acordo com a realidade dos indivíduos. Desse modo, buscou-se identificar como as pessoas vislumbram seu futuro de duas maneiras distintas: a primeira por meio de orçamentos e a segunda através de alguma forma de planejamento pessoal.

Os dados da pesquisa apontam que os homens costumam fazer mais orçamento do que as mulheres, ainda que ambos apresentem altos percentuais quando abordados sobre seus hábitos de compra. Já no que se refere à idade das pessoas que fazem orçamento, não foram identificadas grandes variações entre as faixas etárias, o que permite afirmar que não há correlação entre a idade e o hábito de fazer orçamentos. Ainda, o perfil dos respondentes no que diz respeito aos níveis de escolaridade apresentam percentuais significativos em relação ao hábito de orçar.

Quanto ao perfil dos indivíduos que planejam sua vida pessoal, independentemente de se tratar de um modelo apresentado ou legitimado pela literatura, identificou-se que $75 \%$ dos respondentes, tanto do sexo feminino quanto do masculino, o realizam. Além disso, constatou-se que as pessoas que se encontram na faixa etária de 26 a 30 anos são os que mais planejam sua vida no âmbito pessoal. No que tange ao nível de escolaridade, um "achado" que merece destaque é o 
fato de os doutores apresentarem o menor percentual de utilização do planejamento pessoal, o que pode remeter à conclusão de que o hábito de planejar é mais comum nas pessoas que ainda estão buscando seu posicionamento profissional. Ainda no que diz respeito à prática de planejamento no âmbito pessoal, nota-se que a maioria dos respondentes define horizontes estratégicos anuais, o que vai de encontro aos modelos de planejamento estratégico presentes na literatura que sugerem ciclos mais longos. (PEREIRA, 2010)

Uma inferência significativa desta pesquisa está relacionada à ampliação do conceito de riqueza. Conforme apresentado por diversos autores, dentre eles Santos e Almeida (2001), Rodrigues e Shikida (2005) e Neri (2008), a pesquisa aponta que o sentido da riqueza não está associado apenas ao dinheiro, haja vista que $79 \%$ da amostra relacionam o conceito de riqueza com saúde, felicidade, sucesso, paz, bom relacionamento com a família, dentre outros aspectos mais sociais do que econômicos. Nesse panorama, destaca-se que a maioria dos respondentes compra apenas o necessário e busca poupar suas receitas, inclusive, quando questionados acerca do que fariam se ganhassem 100 mil reais, $45 \%$ poupariam esse montante. Além disso, grande parte dos respondentes trabalha para se satisfazer e ajudar os demais ou porque precisa de dinheiro.

A literatura aponta princípios como persistência, disciplina, determinação, perseverança e vontade de ficar "rico" como importantes para que os indivíduos consigam alcançar seus objetivos no âmbito pessoal (STANLEY; DANKO, 1999; CALVOSA, 2011; CERBASI, 2009; GODFREY; EDWARDS, 2007), sendo, portanto, elementos que devem fazer parte do escopo de um referencial metodológico de Planejamento Estratégico Pessoal.

Desse modo, com base no perfil dos usuários de planejamento pessoal identificado nesta pesquisa $e$ em conformidade com os princípios apontados pela literatura da área, sugere-se que seja desenvolvido um referencial metodológico de Planejamento Estratégico Pessoal mais consistente e de acordo com a realidade dos indivíduos que realmente almejam um futuro mais próspero.

\section{REFERÊNCIAS}

ALLEN, Robert G. Criando riqueza. 1986. Disponível em: <http://www.terremoto.com.br/download/ CriandoRiqueza1.pdf $>$. Acesso em: 8 jul. 2012.

\section{AUGUSTIN, Eziane Samara. Planejamento pessoal} e sua ligação com o Planejamento Estratégico Organizacional. Dissertação (Mestrado) - Centro de Tecnologia - Programa de Pós-graduação em Engenharia de Produção, Universidade Federal de Santa Maria. Santa Maria, RS, 2008.

\section{BEPPLER, Mônica Kulkamp; PEREIRA, Maurício} Fernandes. Planejamento estratégico: a contribuição da cultura organizacional para o processo de implementação da estratégia. São Paulo: Atlas, 2013. v. 3.

CARVALHO, Daniel Estima; ALMEIDA, Martinho Isnard Ribeiro de; WRIGHT, James Terence Coulter. Como colocar em prática o seu plano estratégico? Utilização da ferramenta de implementação e Gestão Estratégica do BSCP (Balanced Scorecard Pessoal) no método PEP - Planejamento Estratégico Pessoal. Disponível em: <http://www.ead.fea.usp.br/eadonline/ grupodepesquisa/publica\%C3\%A7\%C3\%B5es/ Martinho/109.pdf>. Acesso em: 26 set. 2011.

CERBASI, Gustavo. Dinheiro: os segredos de quem tem. São Paulo, SP: Gente, 2003.

\section{Como organizar sua vida financeira:}

inteligência financeira pessoal na prática. 4. ed. Rio de Janeiro, RJ: Elsevier, 2009.

\section{COELHO, Tom. Planejamento estratégico pessoal.}

2008. Disponível em: < http://www.administradores. com.br/informe-se/artigos/planejamento-estrategicopessoal/21124/>. Acesso em: 4 out. 2011.

CYGLER, J. Quem mexeu na minha vida? A fórmula do sucesso e da felicidade, sem estresse. Rio de Janeiro: Elsevier, 2005.

ESTRADA, Rolando Juan Soliz; FLORES, Gilberto Tim; SCHIMITH, Cristiano Descovi. Gestão do tempo como apoio ao Planejamento Estratégico Pessoal. 2011. Disponível em: <http://cascavel.ufsm.br/revistas/ojs-2.2.2/ index.php/reaufsm/article/view/3349/2090>. Acesso em: 26 set. 2012. 
ESTRADA, Rolando Juan Soliz; ALMEIDA, Martinho Isnard Ribeiro de. A eficiência e a eficácia da gestão estratégica: do planejamento estratégico à mudança organizacional. Revista de Ciências da Administração, Florianópolis, v. 9, n. 19, p. 147-178, set.-dez, 2007.

ESTRADA, Rolando Juan Soliz; PEREIRA, Maurício Fernandes; ALMEIDA, Martinho Isnard Ribeiro de. A eficiência e eficácia da gestão estratégica. In: FERREIRA et al. Estratégia em diferentes contextos empresariais: fundamentos, Modelos e Perspectivas. 1. ed. São Paulo, SP: Atlas, 2010.

ESTRADA, Rolando Juan Soliz; MORETTO NETO, Luis; AUGUSTIN, Eziane Samara. Planejamento Estratégico Pessoal. Revista de Ciências da Administração, Florianópolis, v. 13, n. 30, p. 118-145, maio-ago. 2011.

FERREIRA, Manuel Portugal et al. Estratégia

corporativa: implementação, controle e internacionalização. 1. ed. São Paulo-SP: Atlas, 2012.

GODFREY, Neale S.; EDWARDS, Carolina. Dinheiro não dá em árvore: um guia para os pais criarem filhos financeiramente responsáveis. 1. ed. São Paulo, SP: Jardim dos Livros, 2007.

$\mathrm{KICH}$, Juliane Ines Di Francesco; PEREIRA, Maurício Fernandes. Planejamento Estratégico: os pressupostos básicos para uma implantação eficaz. 1. ed. São Paulo, SP: Atlas, 2011.

KOSHY, S. Personal Strategic Planning. Winnipeg: Compass, 2005.

LACERDA, Grecieli Faganello. BÜTTNER, Marcio Marcelo. Educação financeira para crianças entre 10 e 13 anos. TCC - Trabalho de Conclusão de Curso (Graduação) - Curso de Administração na modalidade à distância, Universidade Federal de Santa Catarina. Lages, SC, 2011.

MARTINS, Guilherme Meirelles. Elaboração de um modelo para planejamento estratégico de carreira. TCC - Trabalho de Conclusão de Curso (Graduação) - Departamento de Ciências da Administração, Universidade Federal de Santa Catarina. Florianópolis, SC, 2010.
MINTZBERG, H. The Fall and Rise of Strategic Planning. Harvard Business Review, p. 107-114, 1994.

MORITZ, Gilberto de Oliveira; MORITZ, Mariana Oliveira; PEREIRA, Maurício Fernandes. Planejamento por cenários prospectivos: referencial metodológico baseado em casos para a aplicação prática nas organizações. 1. ed. São Paulo, SP: Atlas, 2012.

NERI, Marcelo Côrtes. Dinheiro traz a felicidade? 2008. Disponível em: <http://www.cps.fgu.br/cps/ pesquisas/Politicas_sociais_alunos/2012/Site/BES_ Felicidade.pdf $>$. Acesso em: 8 jul. 2012.

OLIVEIRA, Gláucia Londero de. Desenvolvimento de um sistema computacional de apoio ao Planejamento Estratégico Pessoal. Dissertação (Mestrado) - Centro de Tecnologia - Programa de Pósgraduação em Engenharia de Produção, Universidade Federal de Santa Maria. Santa Maria, RS, 2009.

PASTORINO, Carlos Juliano Torres. Minutos de sabedoria. Rio de Janeiro, RJ: Vozes, 1966.

PEREIRA, Maurício Fernandes. Planejamento estratégico: teorias, modelos e processos. 1. ed. São Paulo, SP: Atlas, 2010.

PRIMON, Ana Carolina. Planejamento e controle financeiro - um estudo junto às consultoras $e$ consultores da Natura. TCE - Trabalho de Conclusão de Estágio (Graduação) - Departamento de Ciências da Administração, Universidade Federal de Santa Catarina. Florianópolis, SC, 2011.

RIGBY, D.; Bilodeau, B. Management tools and trends. 2013. Bain \& Company, 2013. Disponível em: <http://www.bain.com/Images/BAIN_BRIEF_ Management_Tools_\%26_Trends_2013.pdf $>$. Acesso em: 2 jul. 2013.

RIOS, Dermival Ribeiro. Dicionário global da Língua Portuguesa ilustrado. São Paulo, SP: DCL - Difusão Cultural do Livro Ltda., 2003.

RODRIGUES, Odirlei Aparecido; SHIKIDA, Pery

Francisco Assis. Economia e felicidade: elementos teóricos e evidências empíricas. Pesquisa \& Debate, São Paulo, v. 16, n. 1(27), p. 80-120, 2005. 
SANTOS, Hermes Mendes; ALMEIDA, Martinho Isnard Ribeiro de. Novos Fatores Geradores de Riqueza. In: $\mathrm{V}$ SemeAd - SEMINÁRIOS EM ADMINISTRAÇÃO, 5, 2001, São Paulo. Anais... São Paulo, 2001.

SEIWERT, L. J. Se Tiver pressa, ande devagar. São Paulo: Fundamento Educacional, 2004.

SERRA, Fernando Antônio Ribeiro. Os pilares da estratégia: estudos de caso de cinco empresas líderes. In: FERREIRA et al. Estratégia em diferentes contextos empresariais: Fundamentos, Modelos e Perspectivas. 1. ed. São Paulo, SP: Atlas, 2010.

SILVEIRA, Aline Maria de Oliveira Lopes. Ferramenta de diagnóstico para organizações complexas.

Dissertação (Mestrado) - Programa de Pós-graduação em Administração, Universidade Federal de Santa Catarina. Florianópolis, SC, 2010.

SOUZA, Cesar. Você é do tamanho de seus sonhos: estratégias para concretizar projetos pessoais, empresariais e comunitários. São Paulo: Gente, 2003.

O Momento da sua virada: estratégias que definem o sucesso de pessoas e empresas. São Paulo-SP: Gente, 2004.

STANLEY, Thomas J.; DANKO, William D. O Milionário mora ao lado: os surpreendentes segredos dos ricaços americanos. 1. ed. Barueri, SP: Manole Ltda., 1999.

ULAF, Franciane. Planejamento Estratégico Pessoal. ADEPH - Academia de Desenvolvimento e Planejamento Humano. 2002. Disponível em: <http://www. francianeulaf.com/pep>. Acesso em: 26 set. 2011.

VASCONCELOS, Fábio de Souza. O Desenvolvimento espiritual integrado ao Planejamento Estratégico

Pessoal. Dissertação (Mestrado) - Centro de Tecnologia - Programa de Pós-graduação em Engenharia de Produção, Universidade Federal de Santa Maria. Santa Maria, RS, 2010. 